\title{
Construction of a highly enriched marsupial Y chromosome-specific BAC sub-library using isolated $\mathrm{Y}$ chromosomes
}

\author{
N. Sankovic ${ }^{1,2 *}$, M. L. Delbridge ${ }^{1}$, F. Grützner ${ }^{1,3}$, M. A. Ferguson-Smith ${ }^{4}$, P. C. M. O’Brien ${ }^{4}$ \\ \& J. A. Marshall Graves ${ }^{1}$ \\ ${ }^{1}$ Comparative Genomics Group, Research School of Biological Sciences, Australian National University, \\ Canberra ACT 2601, Australia; ${ }^{2}$ Department of Zoology, University of Melbourne, Parkville VIC 3010, \\ Australia; Tel: +61-03-8344-6521; Fax:+61-03-8344-7909; E-mail: Sankovic@unimelb.edu.au; ${ }^{3}$ School of \\ Molecular and Biomedical Science, University of Adelaide, Adelaide SA 5005, Australia; ${ }^{4}$ Department of \\ Veterinary Medicine, Cambridge University, Cambridge CB3 OES, UK \\ * Correspondence
}

Received 19 December 2005. Received in revised form and accepted for publication by Herbert Macgregor 13 May 2006

Key words: BAC library, Macropus eugenii, tammar wallaby, Y chromosome

\begin{abstract}
The Y chromosome is perhaps the most interesting element of the mammalian genome but comparative analysis of the Y chromosome has been impeded by the difficulty of assembling a shotgun sequence of the Y. BAC-based sequencing has been successful for the human and chimpanzee $\mathrm{Y}$ but is difficult to do efficiently for an atypical mammalian model species (Skaletsky et al. 2003, Kuroki et al. 2006). We show how Y-specific sub-libraries can be efficiently constructed using DNA amplified from microdissected or flow-sorted Y chromosomes. A Bacterial Artificial Chromosome (BAC) library was constructed from the model marsupial, the tammar wallaby (Macropus eugenii). We screened this library for Y chromosome-derived BAC clones using DNA from both a microdissected Y chromosome and a flow-sorted Y chromosome in order to create a Y chromosome-specific sub-library. We expected that the tammar wallaby Y chromosome should detect $\sim 100$ clones from the 2.2 times redundant library. The microdissected Y DNA detected 85 clones, $82 \%$ of which mapped to the Y chromosome and the flow-sorted Y DNA detected 71 clones, $48 \%$ of which mapped to the Y chromosome. Overall, this represented a $\sim 330$-fold enrichment for $\mathrm{Y}$ chromosome clones. This presents an ideal method for the creation of highly enriched chromosome-specific sub-libraries suitable for BAC-based sequencing of the Y chromosome of any mammalian species.
\end{abstract}

\section{Introduction}

A comparison of the genomes of species is proving to be a powerful tool for the identification of new genes or regulatory elements and to study the function of known genes. Comparative genomics also gives important insights into the evolution of our own genome. Full genome shotgun sequencing has been carried out for the autosomes and the $\mathrm{X}$ chromosome of many mammals, including human, chimpanzee, mouse, rat, cow, dog, opossum and platypus. However, the $\mathrm{Y}$ chromosome has been recalcitrant to shotgun sequencing because of the abundance of repetitive sequences. For this reason females are invariably chosen for full genome sequencing.

This has greatly hampered the comparative analysis of the mammal $\mathrm{Y}$ chromosome, which is an extraordinary chromosome especially in terms of 
evolution, sequence composition and function. The mammalian $\mathrm{Y}$ carries the male sex-determining gene and therefore is almost entirely excluded from recombination with the $\mathrm{X}$ chromosome. As a result of the lack of recombination the $\mathrm{Y}$ chromosome has been degraded into a relic containing few active genes among large stretches of repetitive sequences (reviewed in Charlesworth \& Charlesworth 2000, Graves 2006). Although most $Y$ genes are relics of genes once shared with the $\mathrm{X}$, they are largely specialized for a male-specific function. Comparative studies have shown that $\mathrm{Y}$ chromosomes of different mammals have degraded to different extents, having different sized $\mathrm{X}-\mathrm{Y}$ shared (pseudoautosomal) regions and somewhat different subsets of genes (Graves et al. 1998).

Despite its gene paucity there is considerable interest in the gene content of the human $\mathrm{Y}$ chromosome, which has several sex-specific functions, including male sex determination and spermatogenesis (Sinclair et al. 1990, Vogt et al. 1996). Genes have proved difficult to identify on the Y because of the high content of repetitive DNA on the large $(60 \mathrm{Mb})$ human $\mathrm{Y}$ chromosome. The testisdetermining factor $S R Y$ was discovered in 1990 using a positional cloning approach (Sinclair et al. 1990), and several other genes (DAZ, TSPY, RBMY), whose functions are still debated, were cloned from deletion intervals over the next decade (Vogt et al. 1996).

The euchromatic $30 \mathrm{Mb}$ region of the human $\mathrm{Y}$ has now been completely sequenced, and the malespecific region has been shown to contain only 78 active genes, coding for only 27 unique proteins (Skaletsky et al. 2003). Most Y genes are relics of genes once shared with the X. Even genes specialized for a male-specific function, such as the candidate spermatogenesis gene $R B M Y$, the candidate gonadoblastoma gene TSPY, the testis-specific gene $A T R Y$, and the testis-determining gene SRY have widely expressed partners on the $\mathrm{X}$ from which they obviously diverged (Foster \& Graves 1994, Delbridge et al. 1999, 2004, Pask et al. 2000), so the evolution of their control is of particular interest. Comparisons of the $\mathrm{Y}$ chromosomes of different species have been important for an understanding of the function, as well as the evolution, of the Y. The chimpanzee $\mathrm{Y}$ has recently been largely sequenced (Hughes et al. 2005), and sequence of the mouse $\mathrm{Y}$ is in the assembly phase. However, these sequencing projects are unlikely to be extended to other mammals.

Comparisons between the $\mathrm{Y}$ chromosomes of humans and their distant mammalian relatives, marsupials, have been particularly informative. Comparative mapping showed that the small $10 \mathrm{Mb}$ marsupial Y chromosome represents the ancient region of the mammalian proto-Y chromosome and shares the same set of critical male-specific genes (Graves 1995, Waters et al. 2001), as well as marsupial-specific genes such as ATRY (Pask et al. 2000). However, it lacks a large region added to the sex chromosomes in the eutherian lineage, and seems to be relatively free of repetitive sequences (Toder et al. 2000). The demonstration that the human Yborne $Z F Y$ gene had only an autosomal homolog in marsupials was the first piece of evidence that $Z F Y$ is not the testis-determining gene in eutherians (Sinclair et al. 1988).

In order to sequence the $\mathrm{Y}$ chromosome of a marsupial, the creation of a marsupial $Y$ chromosome-specific Bacterial Artificial Chromosome (BAC) sub-library is essential. We identified clones originating from the $\mathrm{Y}$ of the model kangaroo Macropus eugenii (the tammar wallaby) by screening a $2.2 \times$ BAC library (Sankovic et al. 2005) using DNA from physically isolated tammar $\mathrm{Y}$ chromosomes. We used DNA from both a microdissected $\mathrm{Y}$ chromosome and a flow-sorted $\mathrm{Y}$ chromosome, and compared the efficacy of the two sources. The resulting sub-library has proved critical for analysis, gene finding and sequencing of the tammar wallaby Y chromosome.

\section{Materials and methods}

Cell culture and fluorescence in-situ hybridization (FISH)

Male tammar skin fibroblast cells were grown from ear puncture tissue held under Environment ACT permits LI2002270 (June 2003) and LI200325 (June 2004), and tammar metaphase chromosome spreads were prepared according to Toder et al. (1997a). The physical locations of isolated BAC clones were determined by labeling $25 \mathrm{ng}-1 \mu \mathrm{g}$ of DNA from BAC clones with digoxygenin and localizing to 
tammar metaphase chromosome spreads by FISH, using the technique described by Toder et al. (1997a).

\section{Macropus eugenii BAC library}

The construction of a BAC library from the tammar wallaby was described previously (Sankovic et al. 2005). The library consists of 55296 clones arrayed onto three hybridization filters. The average insert size of the library is $108 \mathrm{~kb}$, and it is estimated to represent a 2.2 times coverage of the genome.

\section{Microdissection of the $Y$ chromosome}

Microdissection was performed as described previously (Grützner et al. 2002). Briefly, metaphase chromosomes were prepared and the fresh cell suspensions dropped onto coverslips, air-dried and stained with $10 \%$ Geimsa. Chromosomes were microdissected under a Zeiss Axiovert microscope. A sterile glass needle was controlled by a three-dimen- sional Eppendorf micromanipulator (5171), and the microdissected material was transferred into a drop of collection media (10 mM Tris- $\mathrm{HCl}$ (pH 7.5), $10 \mathrm{mM}$ $\mathrm{NaCl}, 0.1 \%$ SDS, $50 \%$ glycerol and $0.5 \mathrm{mg} / \mathrm{ml}$ proteinase K). Chromosomal DNA was amplified by DOP-PCR by adding the DNA to a $20 \mu \mathrm{l}$ reaction containing $25 \mathrm{mM} \mathrm{MgCl}_{2}, 100 \mu \mathrm{M}$ DOP primer, $5 \mathrm{mM}$ dNTPs, and $5 \mathrm{U} / \mu \mathrm{l} \mathrm{Taq}$, and amplified using the PCR conditions of: $95^{\circ} \mathrm{C} 5^{\prime} \rightarrow 94^{\circ} \mathrm{C} 1^{\prime} / 56^{\circ} \mathrm{C}$ $1^{\prime} / 72^{\circ} \mathrm{C} 2^{\prime} \times 25 \rightarrow 72^{\circ} \mathrm{C} \rightarrow 4^{\circ} \mathrm{C} \infty$.

\section{Flow-sorted Y chromosome}

Tammar wallaby chromosomes were flow-sorted as described previously (Rens et al. 1999), and amplified as described for the microdissected chromosome.

Completeness and Y specificity of DNA from the microdissected and flow-sorted $\mathrm{Y}$ chromosome was verified by labeling the chromosomal DNA with digoxygenin or biotin and hybridizing back to $M$. eugenii metaphase spreads using FISH.

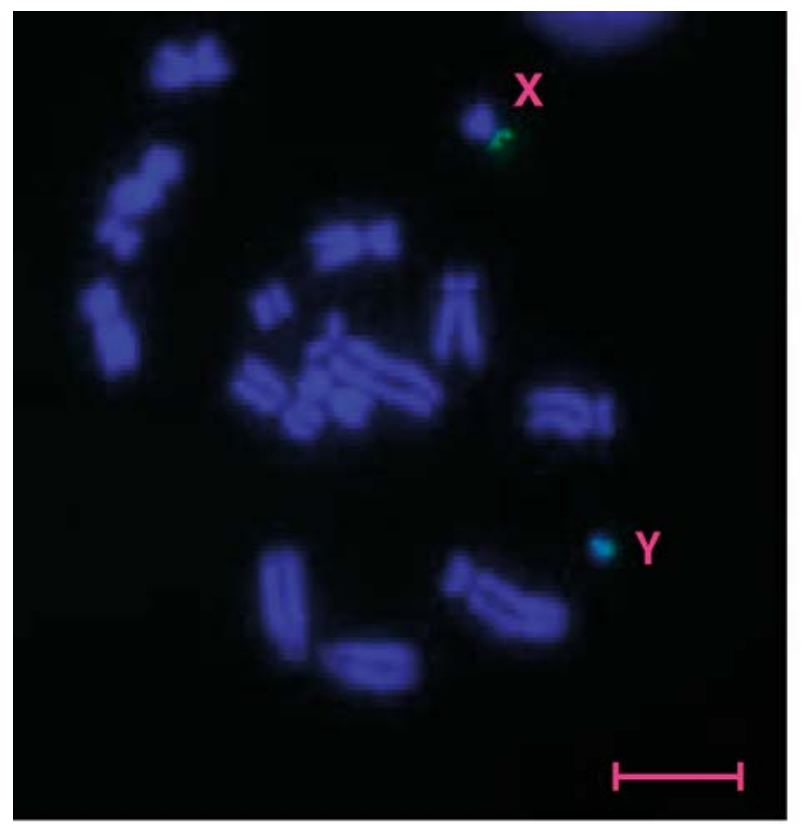

A

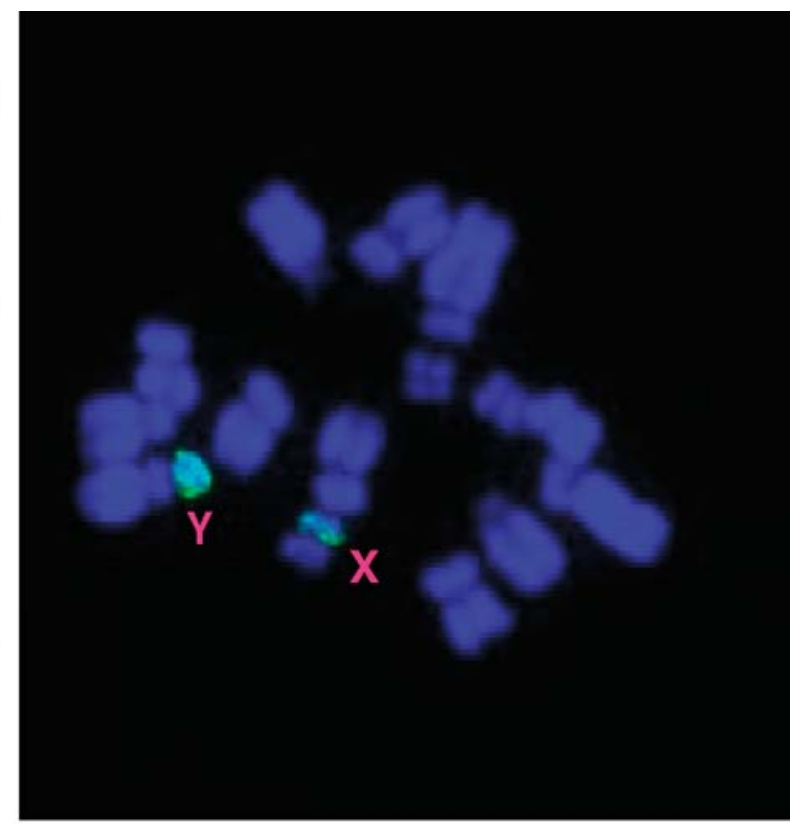

B

Figure 1. A: Biotin-labeled DNA from the microdissected tammar Y chromosome hybridized to a tammar metaphase chromosome spread. The chromosome paints the entire $\mathrm{Y}$ chromosome as well as cross-hybridizing to the distal short arm of the $\mathrm{X}$ chromosome. B: The digoxygenin-labeled flow-sorted tammar Y chromosome hybridized to a tammar metaphase chromosome spread. The chromosome paints the entire $\mathrm{Y}$ chromosome as well as showing cross-hybridization to the $\mathrm{X}$ chromosome. Bar $=10 \mu \mathrm{m}$. 


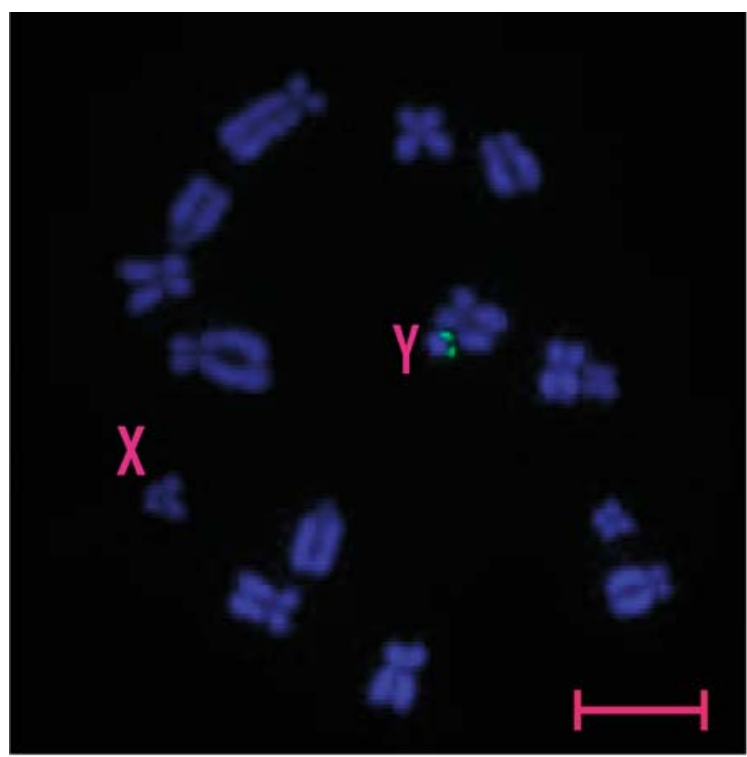

A

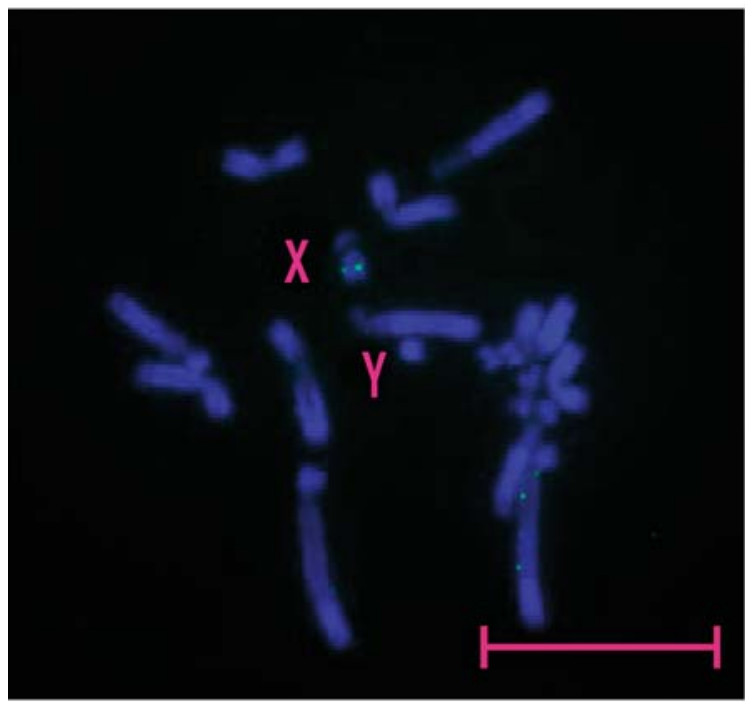

C

Screening the BAC library

To screen the BAC library, 25 ng of Y chromosomal DNA amplified from microdissected or flow-sorted $\mathrm{Y}$ chromosomes were labeled with $\left[\alpha-{ }^{32} \mathrm{P}\right]$ dATP using the MegaPrime DNA Labeling Kit (Amersham BioSciences) according to the manufacturer's instructions. BAC library filters were pre-hybridized in 100

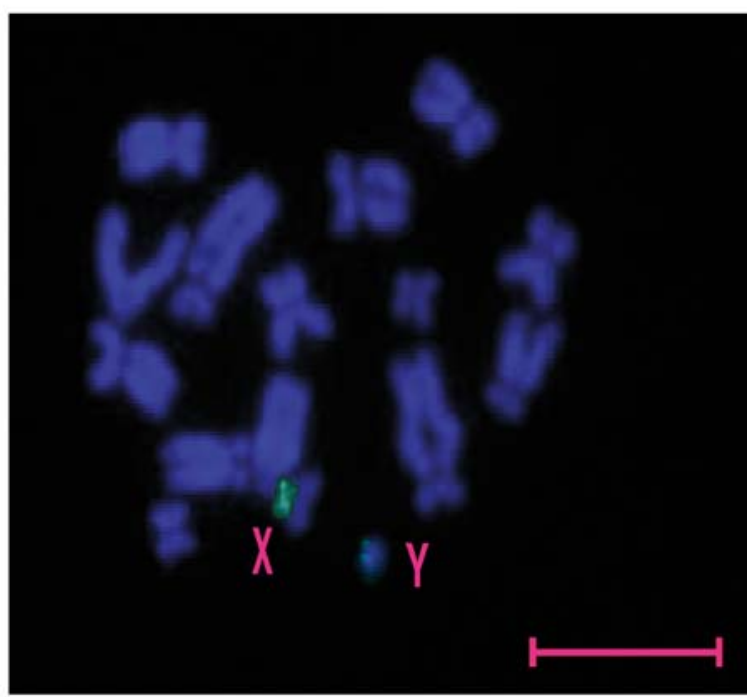

B

Figure 2. BAC clones detected by DNA from microdissected and flow-sorted Y chromosomes were all individually mapped by FISH back to tammar metaphase chromosome spreads to verify their $\mathrm{Y}$ chromosome origin. A: BAC clone mapping to the $\mathrm{Y}$ chromosome; B: BAC clone mapping showing the crosshybridization to the NOR region of the X chromosome; C: BAC clone localized to $\mathrm{Xq}$ but showing no hybridization to the $\mathrm{Y}$. Bar $=$ $10 \mu \mathrm{m}$.

$\mathrm{ml}$ of Church's buffer containing 1\% BSA and 100 $\mu \mathrm{l}$ of $10 \mathrm{mg} / \mathrm{ml}$ salmon sperm DNA overnight at $65^{\circ} \mathrm{C}$. Sheared male $M$. eugenii genomic DNA was used to suppress highly repetitive elements shared by the Y chromosome and other chromosomes. The filters were then hybridized for $24 \mathrm{~h}$ at $65^{\circ} \mathrm{C}$ with each of the two probes. Filters were washed at low stringency $(2 \times \mathrm{SSC} / 0.1 \% \mathrm{SDS})$ for $2 \times 20 \mathrm{~min}$ at $65^{\circ} \mathrm{C}$, 
and then at medium stringency $(1 \times \mathrm{SSC} / 0.1 \% \mathrm{SDS})$ for $2 \times 20 \mathrm{~min}$ at $65^{\circ} \mathrm{C}$ if needed. Filters were exposed to X-OMAT (Kodak) film for 1-10 days. Positive clones were identified manually.

\section{Results}

The tammar wallaby, like all marsupials, has a low diploid chromosome number $(2 \mathrm{n}=14)$ of very large chromosomes (reviewed in Alsop et al. 2005). The $\mathrm{Y}$ chromosome of the tammar wallaby is the smallest element of the genome, representing $<2 \%$ of the haploid male genome. It was easily identifiable for microdissection. Five Y chromosomes were carefully collected and pooled. Figure 1a shows that the chromosome paint covered the whole $\mathrm{Y}$ chromosome, and showed cross-hybridization to the distal short arm of the $\mathrm{X}$ chromosome in the area of the nucleolus organizer region (NOR).

The flow karyotype of tammar chromosomes (Rens et al. 1999) shows excellent separation of the chromosomes. The peak representing 300-500 Y chromosomes yielded DNA that gave the same hybridization pattern as the microdissected $\mathrm{Y}$ and painted the entire $\mathrm{Y}$ and the distal short arm of the $\mathrm{X}$ (Figure 1b).

In order to obtain Y-specific BAC clones we screened the $2.2 \times$ tammar BAC library with DNA amplified from microdissected and flow-sorted $\mathrm{Y}$ chromosomes in the presence of sheared male $M$. eugenii genomic DNA to suppress highly repetitive elements shared with other chromosomes. Despite the complexity of the probes, very low levels of background hybridization were seen in both experiments, and signals were intense and specific, indicating that both probes were highly enriched for Y-specific sequence and the levels of suppression were appropriate.

The microdissected $\mathrm{Y}$ chromosome DNA detected 85 positive BAC clones, and the flow-sorted $\mathrm{Y}$ chromosome DNA detected 71 BAC clones. From a total of 156 clones identified 15 were detected by both the microdissected and the flow-sorted Y chromosomal DNA. In addition three BAC clones were already known to map to the Y chromosome, and contain Y-borne genes. This demonstrated that this method is an effective way to isolate chromosome-specific BAC clones.
The 85 BACs detected by DNA from the microdissected Y chromosome and 71 BACs detected by DNA from the flow-sorted $\mathrm{Y}$ chromosome, were all individually mapped by FISH to tammar metaphase chromosome spreads to verify their $\mathrm{Y}$ chromosome origin (Figure 2). Of the 85 microdissected $\mathrm{Y}$ chromosome clones, $69(82 \%)$ were found to map to the $\mathrm{Y}$ chromosome. Of the 71 clones that were isolated with the flow-sorted $\mathrm{Y}$ chromosome, 35 (48\%) mapped to the Y chromosome. Of the $52 \mathrm{BAC}$ clones that mapped to locations other than the $\mathrm{Y}$, all mapped to a single location in the genome, eight on the $\mathrm{X}$ chromosome (in the $\mathrm{X}$-specific region) and 44 on autosomal chromosomes.

\section{Discussion}

A Y chromosome-specific BAC library was constructed from the model marsupial, the tammar wallaby (Macropus eugenii), by screening a complete genomic BAC library with DNA from both a microdissected $\mathrm{Y}$ chromosome and a flow-sorted $\mathrm{Y}$ chromosome. The microdissected $\mathrm{Y}$ chromosome DNA detected 85 clones, $82 \%$ of which mapped to the $\mathrm{Y}$ chromosome, and the flow-sorted Y DNA detected 71 clones, $48 \%$ of which mapped to the $\mathrm{Y}$ chromosome. Overall, this represented a $\sim 330$-fold enrichment for $\mathrm{Y}$ chromosome clones in the $\mathrm{Y}$ chromosome-specific sub-library.

The use of DNA from whole chromosomes as probes for creating sub-libraries from whole genomic libraries is a technique that has not yet been widely implemented. Using a flow-sorted human chromosome 22 to probe a human BAC library (Kim et al. 1995a) resulted in a sub-library with a 20-fold enrichment of clones for chromosome 22, with $40 \%$ of the hybridized clones being mapped to chromosome 22. Kim et al. (1995b) estimate that this sublibrary represents at least 2.5 times coverage of chromosome 22, and FISH mapping data indicate that all regions of chromosome 22 are well represented. Human chromosome 21 was used as a control as both chromosomes 21 and 22 contain extensive ribosomal repeat sequences, and deletion of those BAC clones appearing in both chromosome 21 and 22 library screens reduced the number of nonspecific hybridization to clones containing repetitive 
elements. Subsequent to the current study, Grützner et al. (2004) employed a similar approach to obtain male-specific sequences from the platypus; however this study has yielded no genes to date.

To our knowledge the technique of using a whole microdissected chromosome has not previously been applied to screen a whole genomic library. However, microdissection of a single chromosome band frequently amplified in human cancers was used to prepare a probe and screen a human chromosome 12 cosmid library to create a cosmid sub-library representing the amplified DNA (Elkahloun et al. 1996). This technique identified 700 clones, and subsequent mapping showed that $60 \%$ were derived from this region.

Problems encountered with this technique derived from PCR amplification of the microdissected chromosome using degenerate oligonucleotide primers that, although they theoretically amplify any sequence, do introduce a bias for certain chromosome regions in the probe. This problem can be reduced by microdissecting multiple copies which will lead to a better representation of DNA sequences of the entire chromosome. In addition, microdissection of individual pufferfish chromosomes was used on pufferfish cosmid and cDNA libraries, which resulted in the isolation of chromosome-specific cosmid clones and cDNAs (Grützner et al. 2002, and unpublished data).

In this case screening the tammar BAC library with DNA from both a flow-sorted and a microdissected tammar Y chromosome to create a chromosomespecific BAC sub-library was more successful than previously described approaches using one or the other source to obtain chromosome-specific BACs from other species. In our case this may also be because of the evolutionary isolation of the Y chromosome from the rest of the genome by its lack of recombination (reviewed in Charlesworth \& Charlesworth 2000). This means that it is possible to use DNA from an entire chromosome without being inundated with false-positive clones. Using these methods, alongside the more traditional approach of using gene-specific probes for known genes on the tammar Y chromosome (Sankovic, unpublished data), it was possible to identify BAC clones derived from the tammar Y chromosome. Overall, 104 different BACs were recovered that mapped to the tammar $\mathrm{Y}$ chromosome. This represents a success rate of $\sim 70 \%$, and a $\sim 330$-fold enrichment of Y chromo- some clones when compared to the original library. In contrast, no Y BACs have been recovered by random characterization of more than 100 BACs. This therefore represents a highly efficient means to isolate BACs originating from the Y chromosome.

Between the two techniques, 104 clones were recovered from the $\mathrm{Y}$, which is about the number expected from the size of the tammar wallaby $\mathrm{Y}$ chromosome. However, the recovery of only 15 BAC clones that were hybridized by both microdissected and flow-sorted Y chromosome DNA indicates that the two probes represent different but overlapping fractions of the Y. This may be due to the limited sequence representation and additional rounds of DOP-PCR amplification required to obtain sufficient DNA from five microdissected $\mathrm{Y}$ chromosomes, compared to that from the 300-500 flow-sorted Y chromosomes. The PCR amplification of microdissected chromosomes can be biased toward sequences that have higher affinity to the DOP primers.

$\mathrm{Y}$-specific BACs were higher amongst those detected by DNA from the microdissected Y chromosome $(82 \%)$ than from the flow-sorted Y chromosome $(48 \%)$. The non-Y clones were distributed evenly over the genome and probably contained repetitive sequences that cross-hybridized to incompletely blocked repetitive sequences on the Y. The intensity of the hybridization signal of the chromosomal DNA on the BAC library filters was not correlated to the final map location of the clone.

Of the selected BAC clones that mapped to the Y, several produced diffuse signals on the heterochromatic region of the long arm of the $\mathrm{Y}$, and also the short arm of the X. Toder et al. (1997b) explained this observation by the translocation of a Nucleolus Organizer Region (NOR), which includes rDNA and associated heterochromatin, to the $\mathrm{X}$ and $\mathrm{Y}$ chromosomes early in macropodid evolution. This autosomal addition the $\mathrm{Y}$ chromosome underwent the same degeneration of the rest of the Y. In one marsupial species the rDNA cistrons are still apparent, but in other macropodids, including tammar, only the heterochromatin remains (Toder et al. 1997b). The cross-hybridization is evidence of this remaining homology. The repetitive sequence shared between $\mathrm{Xp}$ and the middle of $\mathrm{Yq}$ does not pair, and the tammar wallaby, like other marsupials (Sharp 1982), has no PAR. The BAC clones showing this hybridization pattern must therefore have originated from the NOR-bearing segment that is shared between $\mathrm{Xp}$ 
and Yq. These BAC clones show an identical mapping pattern to heterochromatin revealed by C-banding and chromomycin A3 banding of the tammar X chromosome (Alsop et al. 2005).

These Y-specific BACs are the basis for ongoing efforts to map and ultimately sequence the tammar $\mathrm{Y}$ chromosome. By sequencing three BAC clones that map uniquely to the short arm of the tammar $\mathrm{Y}$ chromosome, four known Y-borne genes and three completely novel genes have been identified (Sankovic, unpublished data). Thus, screening even a 2.2 times BAC library with DNA from both microdissected and flow-sorted chromosomes allowed the recovery of unique $\mathrm{Y}$ chromosome clones, and the creation of a highly enriched Y chromosome-specific sub-library.

Tammar Y chromosome DNA is unlikely to be directly useful for screening BAC libraries of related species, since it does not paint the $\mathrm{Y}$ of other species. $\mathrm{Y}$ repetitive sequence is rarely shared across species (Toder et al. 2000). However, the same technique could be applied to isolate Y-specific BACs from any of the mammals currently the subject of whole genome sequencing of a female animal (such as the dog, other primates, elephant, aardvark, opossum and platypus), as well as the female-specific $\mathrm{W}$ chromosome of reptile species.

Although the $\mathrm{Y}$ chromosome may be especially amenable to this approach because its genetic isolation promotes the evolution of Y-unique sequences (Toder et al. 2000), this technique could potentially be applied to isolating chromosome-specific libraries from a sex chromosome or autosome of interest from any species not subject to genome sequencing. It could therefore develop into a useful tool to isolate chromosomespecific clones for comparative genomics for a range of genomes of non-model and exotic animals.

\section{References}

Alsop A, Miethke P, Rofe R et al. (2005) Characterizing the chromosomes of the Australian model marsupial Macropus eugenii (tammar wallaby). Chromosome Res 13: 627-636.

Charlesworth B, Charlesworth D (2000) The degeneration of Y chromosomes. Phil Trans $R$ Soc Lond B Biol Sci 355: 15631572.

Delbridge ML, Lingenfelter PA, Disteche CM, Graves JAM (1999) The candidate spermatogenesis gene Rbmy has a homologue on the human X chromosome. Nat Genet 22: 223-224.
Delbridge ML, Longepied G, Depetris D et al. (2004) Tspy, the candidate gonadoblastoma gene on the human Y chromosome, has a widely expressed homologue on the $\mathrm{X}$ - implicaspace]tions for Y chromosome evolution. Chromosome Res 12: 345-356.

Elkahloun AG, Meltzer PS, Guan XY, McNinch JS, Trent JM, de Jong PJ (1996) Isolation of a cosmid sublibrary for a region of chromosome 12 frequently amplified in human cancers using a complex chromosome microdissection probe. Genomics 31 : 343-347.

Foster JW, Graves JAM (1994) An SRY-related sequence on the marsupial $X$ chromosome: implications for the evolution of the mammalian testis-determining gene. Proc Natl Acad Sci USA 91: $1927-1931$.

Graves JAM (1995) The origin and function of the mammalian Y chromosome and Y-borne genes - an evolving understanding. Bioessays 17: 311-320.

Graves JAM (2006) Sex chromosome specialization and degeneration in mammals. Cell 124: 901-914.

Graves JAM, Wakefield M, Toder R (1998) The origin and evolution of the pseudoautosomal regions of the human sex chromosome. Hum Mol Genet 7: 1991-1996.

Grützner F, Crollius HR, Lütjens G et al. (2002) Four-hundred million years of conserved synteny of human $\mathrm{Xp}$ and $\mathrm{Xq}$ genes on three tetraodon chromosomes. Genome Res 12: 13161322.

Grützner F, Rens W, Tsend-Ayush E et al. (2004) In the platypus a meiotic chain of ten sex chromosomes shares genes with the bird $\mathrm{Z}$ and mammal $\mathrm{X}$ chromosomes. Nature 432: 913-917.

Hughes JF, Skaletsky H, Pyntikova T et al. (2005) Conservation of Y-linked genes during human evolution revealed by comparative sequencing in chimpanzee. Nature 437: 100-103.

Kim UJ, Shizuya H, Deaven L, Chen XN, Korenberg JR, Simon MI (1995a) Selection of a sublibrary enriched for a chromosome from total human bacterial artificial chromosome library using DNA from flow sorted chromosomes as hybridization probes. Nucleic Acids Res 23: 1838-1839.

Kim UJ, Shizuya H, Chen XN et al. (1995b) Characterization of a human chromosome 22 enriched bacterial artificial chromosome sublibrary. Genet Anal 12: 73-79.

Kuroki Y, Toyoda A, Noguchi H et al. (2006) Comparative analysis of chimpanzee and human $\mathrm{Y}$ chromosomes unveils complex evolutionary pathway. Nat Genet 38(2): 158-167.

Pask A, Renfree MB, Graves JAM (2000) The human sexreversing Atrx gene has a homologue on the marsupial Y chromosome, Atry: implications for the evolution of mammalian sex determination. Proc Natl Acad Sci USA 97: 13198-13202.

Rens W, O'Brien PC, Yang F, Graves JAM, Ferguson-Smith MA (1999) Karyotype relationships between four distantly related marsupials revealed by reciprocal chromosome painting. Chromosome Res 7: 461-474.

Sankovic N, Bawden W, Martyn J, Graves JAM, Zuelke K (2005) Construction of a marsupial BAC library from the model Australian marsupial, the tammar wallaby (Macropus Eugenii). Aust J Zool 53: 389-393.

Sharp P (1982) Sex chromosome pairing during male meiosis in marsupials. Chromosoma 86: 27-47.

Sinclair AH, Foster JW, Spencer JA et al. (1988) Sequences homologous to Zfy, a candidate human sex-determining gene, are autosomal in marsupials. Nature 336: 780-783. 
Sinclair AH, Berta P, Palmer MS et al. (1990) A gene from the human sex-determining region encodes a protein with homology to a conserved DNA-binding motif. Nature 346: 240-244.

Skaletsky H, Kuroda-Kawaguchi T, Minx PJ et al. (2003) The male-specific region of the human Y chromosome is a mosaic of discrete sequence classes. Nature 423: 825-837.

Toder R, O’Neill RJ, Wienberg J, O’Brien PC, Voullaire L, Graves JAM (1997a) Comparative chromosome painting between two marsupials: origins of an $\mathrm{Xx} / \mathrm{Xy} 1 \mathrm{y} 2$ sex chromosome system. Mamm Genome 8: 418-422.

Toder R, Wienberg J, Voullaire L, O'Brien PC, Maccarone P, Graves JAM (1997b) Shared DNA sequences between the X and $\mathrm{Y}$ chromosomes in the tammar wallaby - evidence for indepen- dent additions to eutherian and marsupial sex chromosomes. Chromosoma 106: 94-98.

Toder R, Wakefield MJ, Graves JAM (2000) The minimal mammalian $\mathrm{Y}$ chromosome - the marsupial $\mathrm{Y}$ as a model system. Cytogenet Cell Genet 91: 285-292.

Vogt PH, Edelmann A, Kirsch S, Henegariu O, Hirschmann P, Kiesewetter F (1996) Human Y chromosome azoospermia factors (Azf) mapped to different subregions in Yq11. Hum Mol Genet 5: 933-943.

Waters PD, Duffy B, Frost CJ, Delbridge ML, Graves JAM (2001) The human Y chromosome derives largely from a single autosomal region added to the sex chromosomes 80-130 million years ago. Cytogenet Cell Genet 92: 74-79. 